\title{
Review
}

\section{The diagnosis and management of pre-invasive breast disease Genetic alterations in pre-invasive lesions}

\author{
Jorge S Reis-Filho ${ }^{1,2}$ and Sunil R Lakhani ${ }^{1,3}$
}

${ }^{1}$ The Breakthrough Toby Robins Breast Cancer Research Centre, Institute of Cancer Research, London, UK
${ }^{2}$ Life and Health Sciences Research Institute, School of Health Sciences, University of Minho, Braga, Portugal
3The Royal Marsden Hospital, Fulham Rd, London, UK

Corresponding author: Sunil R Lakhani (Sunil.Lakhani@icr.ac.uk)

Published: 9 October 2003

Breast Cancer Res 2003, 5:313-319 (DOI 10.1186/bcr650)

(c) 2003 BioMed Central Ltd (Print ISSN 1465-5411; Online ISSN 1465-542X)

\begin{abstract}
The development of modern molecular genetic techniques has allowed breast cancer researchers to clarify the multistep model of breast carcinogenesis. Laser capture microdissection coupled with comparative genomic hybridisation and/or loss-of-heterozygosity methods have confirmed that many pre-invasive lesions of the breast harbour chromosomal abnormalities at loci known to be altered in invasive breast carcinomas. Current data do not provide strong evidence for ductal hyperplasia of usual type as a precursor lesion, although some are monoclonal proliferations; however, atypical hyperplasia and in situ carcinoma appear to be nonobligate precursors. We review current knowledge and the contribution of molecular genetics in the understanding of breast cancer precursors and preinvasive lesions.
\end{abstract}

Keywords: atypical ductal hyperplasia, comparative genomic hybridisation, ductal carcinoma in situ, lobular carcinoma in situ, loss of heterozygosity

\section{Introduction}

The multistep model of breast carcinogenesis suggests a transition from normal epithelium to invasive carcinoma via non-atypical and atypical hyperplasia and in situ carcinoma. Within the breast, these proliferations are heterogeneous in their cytological and architectural characteristics. The introduction of mammographic screening has led to the increased detection of pre-invasive disease and has highlighted deficiencies in our understanding and classification of such lesions. The morphological classification of pre-invasive lesions of the breast remains controversial and there has been hope that molecular analysis will clarify the uncertainties.

A multitude of methods have been used for the characterisation of pre-invasive breast lesions, including immunohistochemistry, fluorescent in situ hybridisation, analysis of loss of heterozygosity (LOH), comparative genomic hybridisation $(\mathrm{CGH})$, and, more recently, cDNA micro- arrays and proteomics analysis. In this review, we have mainly focused on the genetic abnormalities in pre-invasive lesions of the breast as detected by $\mathrm{LOH}$ and CGH analysis (Table 1). The other techniques have been addressed elsewhere in the series.

\section{Ductal carcinoma in situ}

The analysis of genetic alterations in ductal carcinoma in situ (DCIS) has provided new insights in the biology of these lesions. As with invasive carcinoma, abnormalities of chromosomes 1 and 16 have been identified in some of these cases [1]. The CGH method has been modified for paraffin-embedded material and this has allowed studies on archival material and, in particular, the study of pre-invasive disease [2-8]. CGH analysis of DCIS has demonstrated a large number of alterations, including gains of $1 q, 5 p, 6 q, 8 q, 17 q, 19 q, 20 p, 20 q$, and Xq, and losses of $2 q, 5 q, 6 q, 8 p, 9 p, 11 q, 13 q, 14 q, 16 q, 17 p$, and $22 q$ [2-8]. These alterations are similar to those identified in

$\mathrm{ADH}=$ atypical ductal hyperplasia; $\mathrm{ALH}=$ atypical lobular hyperplasia; $\mathrm{CGH}=$ comparative genomic hybridisation; $\mathrm{DCIS}=$ ductal carcinoma in situ; HUT = hyperplasia of usual type; LCIS = lobular carcinoma in situ; LOH = loss of heterozygosity; NST = no special type. 
Table 1

Summary of the genetic abnormalities detected in pre-invasive lesions of the breast ${ }^{\text {a }}$

\begin{tabular}{|c|c|c|c|c|}
\hline Lesion & Method & Gains $^{b}$ & Losses / LOH / Al ${ }^{\mathrm{b}}$ & erence \\
\hline \multirow[t]{6}{*}{ Normal cells } & s $\mathrm{LOH}$ & - & 2pter, 16q23.1-24.2, 17q21, 17q24 & [17] \\
\hline & $\mathrm{LOH}$ & - & $9 p, 11 p, 13 q, 16 q, 17 p$ & {$[56]$} \\
\hline & $\mathrm{LOH}$ & - & 3p24, 11p15.5, 17p13.1 & [60] \\
\hline & $\mathrm{LOH}$ & - & $1 q, 7 q, 11 p, 16 q, 17 q$ & [61] \\
\hline & $\mathrm{LOH}$ & - & $11 p, 13 q$ & [63] \\
\hline & $\mathrm{LOH}$ & - & $3 p 24.3$ & {$[64]$} \\
\hline \multirow[t]{6}{*}{ HUT } & $\mathrm{CGH}$ & No & No & {$[6]$} \\
\hline & $\mathrm{LOH}$ & - & $\begin{array}{l}2 p t e r, 2 q 35,4 q 25,6 q t e r, 8 p, 9 p, 11 p 15,11 q 23,13 q 13,14 q 24,16 q 21,17 p 13,17 q 11 \\
17 q 21,17 q 25\end{array}$ & [13] \\
\hline & $\mathrm{CGH}$ & $\begin{array}{l}1 q+, 1 q 32-42+ \\
12+, 17 q 21+, 20+\end{array}$ & 8-, 8p12-pter-, 9-, 10p-, 11q14-qter-, 18-, X-, 16q-, 17p-, 20p- & {$[54]$} \\
\hline & $\mathrm{LOH}$ & - & $16 q, 17 p, 17 q$ & {$[55]$} \\
\hline & $\mathrm{LOH}$ & - & $9 p, 11 p, 13 q, 16 q, 17 q$ & {$[56]$} \\
\hline & $\mathrm{CGH}$ & $13 q$ & $1 p, 16 p, 17 q, 19 p, 22 q$ & [57] \\
\hline \multirow[t]{4}{*}{$\mathrm{ADH}$} & $\mathrm{LOH}$ & - & 2 pter, $2 q 35,6 q t e r, 8 p, 9 p, 11 p 15,11 q 23,13 q 13,14 q 24,16 q 21,17 p 13,17 q 11,17 q 21$ & [13] \\
\hline & $\mathrm{LOH}$ & - & $17 q 25,16 q, 17 p$ & {$[52]$} \\
\hline & $\mathrm{LOH}$ & - & $8 p, 16 q, 17 q$ & [53] \\
\hline & $\mathrm{CGH}$ & $\begin{array}{l}1 q, 10,16 p \\
8 q 21-q t e r, 14 q\end{array}$ & 3q11-q21, 8p12-pter, 16q,20, 11q12-13, 16q 16q, 20p, 16q, 17p, 21q11-q21, 16q, 17p & [54] \\
\hline \multirow[t]{2}{*}{ ALH/LCIS } & $\mathrm{CGH}$ & $\begin{array}{l}1 q, 1 q 21-q 32 \\
1 q 25-q t e r, 8 p 11-p 12 \\
12 q 14-q 21\end{array}$ & $7 p, 8 p, 8 p 21-p t e r, 12 q 24,16 q, 17 p, 13 q 12-q 21 ; 16 q ; 17 p 12-p 13$ & [31] \\
\hline & $\mathrm{CGH}$ & $6 q$ & $16 p, 16 q, 17 p, 22 q$ & [32] \\
\hline $\begin{array}{l}\text { Columnar } \\
\text { cell change } \\
\text { /clinging ca }\end{array}$ & $\mathrm{LOH}$ & - & $2 p, 3 p, 11 q, 11 q, 16 q, 16 q, 17 q, 17 q$ & [60] \\
\hline $\mathrm{DCIS}^{\mathrm{c}}$ & See text & See text & See text & text \\
\hline
\end{tabular}

- , none. a For $\mathrm{LOH}$ analyses, only those studies in which more than one chromosomal arm was evaluated were included in the table. ${ }^{b} \mathrm{All}$ chromosomal gains and losses reported in the cited studies (references) were included. For the frequency of each genetic abnormality, please see text and cited references. 'DCIS of different grades harbour distinct chromosomal abnormalities. Genetic abnormalities of nearly all chromosomal arms have been reported in high-grade DCIS. See text for details. ADH, atypical ductal hyperplasia; Al, allelic imbalance; ALH/LCIS, atypical lobular hyperplasia/lobular carcinoma in situ; Columnar cell change/ clinging ca, columnar cell change/clinging carcinoma; DCIS, ductal carcinoma in situ; HUT, hyperplasia of usual type; LOH, loss of heterozygosity.

invasive carcinoma, adding weight to the idea that DCIS is a precursor lesion.

Several lines of evidence support the concept that different types of DCIS show different genetic alterations, suggesting that there may be multiple pathways for the evolution of DCIS $[4,6,8,9]$. Alterations at $16 q$ are much more frequent in low-grade DCIS than in high-grade DCIS, in which alterations at $13 q, 17 q$, and $20 q$ are more frequent $[4,6,7,10]$. Similar findings in invasive carcinomas of low and high grade also support the idea that low-grade and high-grade lesions develop through distinct pathways

rather than by dedifferentiation $[4,6,7,10]$. With the use of microdissection techniques to isolate small microscopic lesions, loss of heterozygosity $(\mathrm{LOH})$ has also been investigated in pre-invasive disease [11-17]. O'Connell and colleagues [11] studied pre-invasive lesions using a variety of chromosomal markers and showed that $50 \%$ of the proliferative lesions and $80 \%$ of the DCIS shared their $\mathrm{LOH}$ patterns with invasive carcinoma. Stratton and colleagues [12] studied cases of DCIS associated with invasive carcinoma and cases of 'pure' DCIS without an invasive component using a limited set of microsatellite markers on chromosomes $7 q, 16 q, 17 p$, and $17 q$. They found a similar frequency of $\mathrm{LOH}$ in both subsets of DCIS to invasive carcinoma, providing further strong evidence 
that DCIS is likely to be a precursor of invasive carcinoma. Several other reports corroborating these seminal studies have been published [13-20].

c-erbB2 (Her-2/neu) protein has been identified in a high proportion $(60-80 \%)$ of DCIS of high-nuclear-grade comedo type but is not common in the low-nuclear-grade forms. Allred and colleagues [21] showed that the expression is higher in invasive carcinoma associated with DCIS than in those without DCIS. This oncogene is very rarely overexpressed in classic lobular carcinoma in situ (LCIS) and its overexpression has been occasionally observed in cases of pleomorphic lobular carcinoma in situ [22,23]. There is no evidence that c-erbB2 is amplified or overexpressed at the protein level in benign proliferative breast diseases or atypical ductal hyperplasia (ADH) [24], which may suggest that c-erbB2 is important in the transition from a 'benign' to a 'malignant' phenotype. The difference in frequencies of expression in in situ and invasive carcinoma remains a mystery. A number of hypotheses have been advanced, suggesting either that the expression is switched off during invasion or that many c-erbB2-positive DCIS do not transform to invasive malignancy. Expression of p53 protein has been demonstrated using immunohistochemistry in high-nuclear-grade DCIS (comedo type) [25]. The mechanism may be gene mutation, but this has been confirmed in only some cases. Like c-erbB2, p53 protein expression is rare in LCIS and has not been demonstrated in atypical ductal hyperplasia or other benign proliferative disease [26]. Done and colleagues [27] demonstrated that $p 53$ mutations found in DCIS and associated invasive cancer were absent from benign proliferative lesions from the same breast.

In summary, a considerable body of evidence indicates that DCIS, particularly of high grade, shares many molecular genetic alterations with invasive carcinoma [4-8,14,15]. Therefore, high-grade DCIS should be considered a direct precursor of invasive carcinoma. Moreover, gain of chromosome 1q and loss of 16q, which are highly prevalent in low-grade DCIS, are frequently found in tubular carcinoma and in tubular, tubulolobular, lobular, and grade 1 invasive ductal carcinomas [4,6,8,28], suggesting that low-grade DCIS is also a direct precursor for certain types of breast carcinomas.

\section{Lobular carcinoma in situ}

Lobular carcinoma in situ of the breast is an uncommon lesion with a distinctive appearance. It is classically composed of discohesive cells with small, monomorphic, hyperchromatic nuclei; however, a pleomorphic variant has been described $[23,29]$. It is occasionally confused with DCIS of low-grade, solid type; however, epidemiological studies show that its biological behaviour and clinical implications are quite different from those of DCIS. It is usually an incidental finding and is not visible on mammo- graphy [29]. The lesions are multifocal and bilateral in a high proportion of cases [29]. The majority of cases are diagnosed in patients aged between 40 and 50 years, a decade earlier than DCIS. Approximately one-fifth of the cases will progress to invasive cancer over a 20- to 25-year follow-up period [29]. Although invasive ductal carcinomas, especially of tubular type, do occur after LCIS, most cases associated with LCIS are infiltrating lobular carcinoma [29]. It has been said that the risk is equal for the two breasts [30]; however, there are data to suggest that the risk is skewed in favour of the ipsilateral breast $[29,31]$. Despite these thorny issues, the epidemiological and pathological features of LCIS have raised questions about its biological nature, and some still consider it a 'marker of increased risk' rather than a true precursor of invasive carcinoma.

In our laboratories, we have carried out CGH analysis on LCIS and atypical lobular hyperplasia [32]. Loss of material from $16 p, 16 q, 17 p$, and $22 q$ and gain of material from $6 q$ have been found at similar high frequencies in both LCIS and atypical lobular hyperplasia. Losses at 1q, 16q, and $17 p$ have also been seen in invasive lobular carcinomas $[8,33]$. LOH data in LCIS are also limited but do demonstrate a similarity between LCIS and infiltrating lobular carcinoma [34,35].

E-cadherin is a candidate tumour suppressor protein coded by a gene on $16 q 22.1$, which is involved in cell-cell adhesion and in cell-cycle regulation through the $\beta$-catenin/Wnt pathway [36]. The majority of invasive ductal carcinomas of no special type (NST) usually exhibit positive staining by immunohistochemistry, whereas the overwhelming majority of invasive lobular carcinomas are negative [37-39]. E-cadherin truncating mutations associated with loss of the wild-type allele ( $\mathrm{LOH}$ at $16 \mathrm{q}$ ) have been observed in LCIS and invasive lobular carcinomas $[38,40,41]$. Berx and colleagues [40] failed to identify any truncating mutations in invasive ductal carcinomas of NST or medullary carcinomas; similar findings were recently reported by Roylance and colleagues [39], who demonstrated lack of E-cadherin mutations in 44 low-grade ductal carcinomas of NST. E-cadherin is expressed in normal epithelium and in most of the cases of DCIS, but staining is rarely seen in LCIS $[23,38,39,42-46]$. Based on this differential expression of E-cadherin in LCIS and DCIS, some authors have advocated the use of antibodies against E-cadherin as an adjunct marker for the differentiation of LCIS from DCIS [23,44-47].

In addition, Vos and colleagues [41] have demonstrated the same truncating mutation in the E-cadherin gene in LCIS and the adjacent invasive lobular carcinoma. The data provide strong evidence for the role of the E-cadherin gene in the pathogenesis of lobular lesions and also support the hypothesis of a precursor role for LCIS. 
Although E-cadherin germline mutations have been implicated in the pathogenesis of familial diffuse gastric carcinoma, there are only anecdotal case reports of lobular carcinoma arising in patients with germline alteration in the gene [36]. In contrast, Rahman and colleagues [46] failed to find any pathogenic E-cadherin germline mutations in 65 patients with LCIS and positive family history of breast carcinoma, thus suggesting that E-cadherin is unlikely to act as a susceptibility gene for LCIS.

\section{Atypical ductal hyperplasia}

ADH is a controversial lesion, which shares some but not all features of DCIS. It poses considerable difficulties in surgical histopathology. In order to address this problem, Page and Rogers [48] laid down criteria for the diagnosis of this entity. Rosai [49] in his study had demonstrated a high interobserver variability in the diagnosis of $\mathrm{ADH}$. However, a subsequent study by Schnitt and colleagues [50], in which the pathologist used Page's criteria, showed an improvement, with complete agreement in $58 \%$ of cases. Within the UK National External Quality Assessment Scheme [51], agreement even among experienced breast pathologists has been low. Lakhani and colleagues [52] demonstrated that LOH identified at loci on $16 q$ and $17 p$ in invasive carcinoma and DCIS is also present in $\mathrm{ADH}$ with a similar frequency. Similar results were reported by Amari and colleagues [53]. O'Connell and colleagues [13] studied 51 cases of $A D H$ at 15 polymorphic loci and found $\mathrm{LOH}$ at at least one marker in $42 \%$ of the cases. The studies demonstrate that morphological overlaps are reflected at the molecular level and raise questions about the validity of separating ADH from DCIS. $\mathrm{CGH}$ analysis of nine cases of $\mathrm{ADH}$ revealed chromosomal abnormalities in five of them [54]. As expected, owing to the morphological overlap with low-grade DCIS, losses of $16 q$ and $17 p$ were the most frequent changes found in $\mathrm{ADH}[54]$.

\section{Hyperplasia of usual type}

O'Connell and colleagues [13] demonstrated that $\mathrm{LOH}$ at many different loci can be identified in hyperplasia of usual type (HUT), with frequencies ranging from 0 to $15 \%$. These figures are similar to those of Lakhani and colleagues [55], who reported data in non-atypical hyperplasia (HUT) dissected from benign breast biopsies. LOH was identified at frequencies ranging from 0 to $13 \%$ at a locus on 17q. These frequencies are much lower than those identified in DCIS and ADH (range 25-55\%). In the series reported by Washington and colleagues [56], 4 of 21 HUTs showed LOH in one to five loci. LOH at $16 q$ (three cases), 9p (three cases), and 13q (two cases) were the most frequent findings [56]. Although CGH analysis of HUTs has demonstrated that the majority of these lesions harbour no chromosomal abnormalities [6,55-57], the picture dramatically changes when they are associated losses of $16 q$ and $17 p$ [54]. In our view, the majority of HUTs do not appear to be precursors of DCIS and IDC, but the precursor potential of a small subset of these lesions cannot be excluded based on the reports of synchronous HUT and invasive breast cancer sharing a common genetic lineage [13].

A word of caution should be voiced, as in the majority of the studies published to date, the contamination of HUTs with neoplastic cells of ADH and DCIS could not be excluded. This issue was recently addressed in a study published by Jones and colleagues [57], in which the authors analysed 14 cases of bilateral HUTs (28 lesions) by $\mathrm{CGH}$. To avoid the inclusion of dubious lesions or contamination of HUTs with neoplastic cells, the authors defined HUTs according to the criteria proposed by the Pathology Working Group on Behalf of the Breast Screening Program and immunohistochemically with antibodies against cytokeratins 5/6. In that study [57], 18 of 28 lesions from 10 of 14 patients harboured chromosomal abnormalities, which ranged from 0 to 5 , with a mean of 1.6. The most common genetic alterations were gains of $13 q$ and losses at $1 p, 16 p, 17 q, 19 p$, and 22q. When paired HUTs from the same patients were compared, only five concordant genetic abnormalities were observed, and only one of these appeared more than once (loss of $17 q$, in two cases). These findings corroborated those reported by O'Connell and colleagues [13], who evaluated multiple foci of HUT affecting the same breast (53 breasts) and found that only $15 \%$ of the lesions within the same breast shared their $\mathrm{LOH}$ phenotype. Altogether, owing to limitations imposed by the currently available methodology, it seems that a relatively small proportion of HUTs are monoclonal, neoplastic proliferations, but the evidence in support of HUT as a precursor of DCIS and IDC is still weak.

\section{Columnar cell lesions}

Columnar cell lesions have been a major source of confusion among breast pathologists, first because they have been reported under several different names, including columnar alteration of lobules, blunt duct adenosis, metaplasie cylindrique, cancerisation of small ectatic ducts of the breast by ductal carcinoma in situ cells with apocrine snouts [58], columnar alteration with prominent apical snouts and secretions [59], and clinging carcinoma in situ [60]. These lesions represent a spectrum that ranges from columnar cell alteration in luminal cells to $\mathrm{ADH}$ and flat/clinging DCIS. Regardless of the fact that there are several lines of evidence showing an association with tubular carcinoma $[59,60]$, only one paper has addressed the genetic abnormalities in these lesions [60]. Moinfar and colleagues [60] demonstrated that $77 \%$ of columnar cell lesions (either with or without atypia) harbour chromosomal abnormalities at least in one locus and the most frequent loci of $\mathrm{LOH}$ were 11q21-23.2, 16q23.1-24.2, and 
$3 p 14.2$ [60]. It is noteworthy that $16 q$ and $11 q$ are frequently lost in tubular carcinomas $[28,60]$. More interestingly, these authors [60] have also shown that otherwise luminal cells with mild nuclear atypia lining ducts at the vicinity of columnar cell lesions may also have loss of genetic material in up to $6 \%$ of the cases.

\section{Normal tissues}

Over the past few years, seven studies have also demonstrated that $\mathrm{LOH}$ identified in invasive carcinoma is already present in morphologically normal lobules [17,36,56,61-64]. Lakhani and colleagues [63] demonstrated that $\mathrm{LOH}$ identified in normal breast epithelial cells is seen independently in luminal and myoepithelial cells, suggesting a common precursor cell for these two types of epithelial cell. Even more thought provoking is the data published by Moinfar and colleagues [17], who demonstrated the presence of concurrent and independent genetic alterations in normal-appearing stromal and epithelial cells located either in the vicinity of or at a distance from the foci of DCIS or IDC. The extent and frequency of alterations and their significance in the multistep carcinogenesis remain unknown at present. It should be noted that in breasts without malignant changes, genetic alterations in normal cells are rather infrequent, subtle, and fairly random [6]. Conversely, one paper has demonstrated that normal lobules and adjacent in situ carcinomas show concordant genetic alterations [17], and another suggested that $\mathrm{LOH}$ in lobular units in terminal ducts in the normal breast is predictive of local recurrence [64].

\section{Conclusion}

Molecular biology and genetics have provided new insights for the comprehension of biology of pre-invasive lesions of the breast. CGH and LOH studies have partially corroborated the multistep model of breast carcinogenesis by demonstrating similar chromosomal abnormalities in $\mathrm{ADH}$ and DCIS. More interestingly, these findings challenge the concept of HUT as a precursor of breast cancer and suggest that columnar cell alteration may be a peculiar form of pre-invasive lesion and, possibly, a precursor of low-grade invasive ductal carcinomas of the breast. These techniques have also demonstrated that different types of in situ breast carcinoma harbour different chromosomal abnormalities, and these findings may reflect the involvement of different pathways in the multistep model of breast carcinogenesis.

We are still in the early phase of molecular analysis of preinvasive lesions. Dramatic advances in the understanding of these lesions may be expected with the development of more flexible microdissection systems (suitable for fresh/frozen samples) and the advent of high-throughputtechnology methods suitable for the evaluation of paraffinembedded tissues (e.g. CGH arrays).
This article is the eighth in a review series on The diagnosis and management of pre-invasive breast disease - current challenges, future hopes, edited by Sunil R Lakhani.

Other articles in the series can be found at http://breast-cancer-research.com/articles/reviewseries.asp?series=bcr_Thediagnosis

\section{Competing interests}

None declared.

\section{Acknowledgements}

JSRF is the recipient of the Gordon Signy International Fellowship Award of the World Association of Societies of Pathology and Laboratory Medicine (WASPALM) and is partially supported by a PhD grant (ref. SFRH/BD/5386/2001) from the Fundação para a Ciência e a Tecnologia (FCT), Portugal.

\section{References}

1. Murphy DS, Hoare SF, Going JJ, Mallon EE, George WD, Kaye SB, Brown R, Black DM, Keith WN: Characterisation of extensive genetic alterations in ductal carcinoma in situ by fluorescence in situ hybridization and molecular analysis. J Natl Cancer Inst 1995, 87:1694-1704.

2. Isola J, DeVries S, Chu L, Ghazvini S, Waldman F: Analysis of changes in DNA sequence copy numbers by coparative genomic hybridization in archival paraffin-embedded tumour samples. Am J Pathol 1994, 145:1301-1308.

3. Kuukasjarvi T, Tanner M, Pennanen S, Karhu R, Kallioniemi OP, Isola J: Genetic changes in intraductal breast cancer detected by comparative genomic hybridization. Am J Pathol 1997, 150: 1465-1471.

4. Buerger $\mathrm{H}$, Otterbach $\mathrm{F}$, Simon R, Schafer KL, Poremba C, Diallo $\mathrm{R}$, Brinkschmidt C, Dockhorn-Dworniczak B, Boecker W: Different genetic pathways in the evolution of invasive breast cancer are associated with distinct morphological subtypes. $J$ Pathol 1999, 189:521-526.

5. Waldman FM, DeVries S, Chew KL, Moore DH 2nd, Kerlikowske $\mathrm{K}$, Ljung BM: Chromosomal alterations in ductal carcinomas in situ and their in situ recurrences. J Natl Cancer Inst 2000, 92: 313-320.

6. Boecker W, Buerger H, Schmitz K, Ellis IA, van Diest PJ, Sinn HP, Geradts J, Diallo R, Poremba C, Herbst H: Ductal epithelial proliferations of the breast: a biological continuum? Comparative genomic hybridization and high-molecular-weight cytokeratin expression patterns. J Pathol 2001, 195:415-421.

7. Aubele M, Mattis A, Zitzelsberger H, Walch A, Kremer M, Welzl G, Hofler $\mathrm{H}$, Werner $\mathrm{M}$ : Extensive ductal carcinoma In situ with small foci of invasive ductal carcinoma: evidence of genetic resemblance by CGH. Int J Cancer 2000, 85:82-86.

8. Buerger $H$, Schmidt $H$, Beckmann A, Zanker KS, Boecker W, Brandt B: Genetic characterisation of invasive breast cancer: a comparison of CGH and PCR based multiplex microsatellite analysis. J Clin Pathol 2001, 54:836-840.

9. Vos CB, ter Haar NT, Rosenberg C, Peterse JL, Cleton-Jansen AM, Cornelisse CJ, van de Vijver MJ: Genetic alterations on chromosome 16 and 17 are important features of ductal carcinoma in situ of the breast and are associated with histologic type. Br J Cancer 1999, 81:1410-1418.

10. Roylance R, Gorman P, Hanby A, Tomlinson I: Allelic imbalance analysis of chromosome $16 q$ shows that grade I and grade III invasive ductal breast cancers follow different genetic pathways. J Pathol 2002, 196:32-36.

11. O'Connell P, Pekkel V, Fuqua S, Osborne CK, Allred DC: Molecular genetic studies of early breast cancer evolution. Breast Cancer Res Treat 1994, 32:5-12.

12. Stratton MR, Collins N, Lakhani SR, Sloane JP: Loss of heterozygosity in ductal carcinoma in situ of the breast. J Pathol 1995, 175:195-201. 
13. O'Connell P, Pekkel V, Fuqua SA, Osborne CK, Clark GM, Allred DC: Analysis of loss of heterozygosity in 399 premalignant breast lesions at 15 genetic loci. J Natl Cancer Inst 1998, 90: 697-703.

14. Shen CY, Yu JC, Lo YL, Kuo CH, Yue CT, Jou YS, Huang CS, Lung JC, Wu CW: Genome-wide search for loss of heterozygosity using laser capture microdissected tissue of breast carcinoma: an implication for mutator phenotype and breast cancer pathogenesis. Cancer Res 2000, 60:3884-3892.

15. Farabegoli F, Champeme MH, Bieche I, Santini D, Ceccarelli C, Derenzini M, Lidereau R: Genetic pathways in the evolution of breast ductal carcinoma in situ. J Pathol 2002, 196:280-286.

16. Regitnig $P$, Moser $R$, Thalhammer $M$, Luschin-Ebengreuth $G$, Ploner F, Papadi H, Tsybrovskyy O, Lax SF: Microsatellite analysis of breast carcinoma and corresponding local recurrences. $J$ Pathol 2002, 198:190-197.

17. Moinfar F, Man YG, Arnould L, Bratthauer GL, Ratschek M, Tavassoli FA: Concurrent and independent genetic alterations in the stromal and epithelial cells of mammary carcinoma: implications for tumorigenesis. Cancer Res 2000, 60:2562-2566.

18. Fujii H, Szumel R, Marsh C, Zhou W, Gabrielson E: Genetic progression, histological grade, and allelic loss in ductal carcinoma in situ of the breast. Cancer Res 1996, 56:5260-5265.

19. Koreth J, Bethwaite PB, McGee JOD: Mutations at chromosome 11q23 in human non-familial breast cancer: a microdissection microsatellite analysis. J Pathol 1995, 176:11-18.

20. Marcello Aldaz C, Chen T, Sahin A, Cunningham J, Bondy M: Comparative allelotype of in situ and invasive human breast cancer: high frequency of microsatellite instability in lobular breast carcinoma. Cancer Res 1995, 55:3976-3981.

21. Allred DC, Clark GM, Molina R, Tandon AK, Schnitt SJ, Gilchrist KW, Osborne CK, Tormey DC, McGuire WL: Overexpression of HER-2/neu and its relationship with other prognostic factors change during the progression of in situ to invasive breast cancer. Hum Pathol 1992, 23:974-979.

22. Gusterson BA, Machin LG, Gullick WJ, Gibbs NM, Powles TJ, Price $P$, McKinna A, Harrison S: Immunohistochemical distribution of c-erbB-2 in infiltrating and in situ breast cancer. Int $J$ Cancer 1988, 42:842-845.

23. Sneige N, Wang J, Baker BA, Krishnamurthy S, Middleton LP: Clinical, histopathologic, and biologic features of pleomorphic lobular (ductal-lobular) carcinoma in situ of the breast: a report of 24 cases. Mod Pathol 2002, 15:1044-1050.

24. Gusterson BA, Machin LG, Gullick WJ, Gibbs NM, Powles TJ, Elliott C, Ashley S, Monaghan P, Harrison S: c-erbB-2 expression in benign and malignant breast disease. $\mathrm{Br} J$ Cancer 1988, 58:453-457.

25. Poller DN, Roberts EC, Bell JA, Elston CW, Blamey RW, Ellis IO: p53 protein expression in mammary ductal carcinoma in situ: relationship to immunohistochemical expression of estrogen receptor and c-erbB-2 protein. Hum Pathol 1993, 24:463-468.

26. Allred DC, O'Connell P, Fuqua SA, Osborne CK: Immunohistochemical studies of early breast cancer evolution. Breast Cancer Res Treat 1994, 32:13-18.

27. Done SJ, Arneson NC, Ozcelik H, Redston M, Andrulis IL: p53 mutations in mammary ductal carcinoma in situ but not in epithelial hyperplasias. Cancer Res 1998, 58:785-789.

28. Buerger H, Otterbach F, Simon R, Schafer KL, Poremba C, Diallo R, Brinkschmidt C, Dockhorn-Dworniczak B, Boecker W: Different genetic pathways in the evolution of invasive breast cancer are associated with distinct morphological subtypes. $J$ Pathol 1999, 189:521-526.

29. Lishman SC, Lakhani SR: Atypical lobular hyperplasia and lobular carcinoma in situ: surgical and molecular pathology. Histopathology 1999, 35:195-200.

30. Goldschmidt RA, Victor TA: Lobular carcinoma in situ of the breast. Semin Surg Oncol 1996, 12:314-320.

31. Etzell JE, Devries S, Chew K, Florendo C, Molinaro A, Ljung BM, Waldman FM: Loss of chromosome 16q in lobular carcinoma in situ. Hum Pathol 2001, 32:292-296.

32. Lu YJ, Osin P, Lakhani SR, Di Palma S, Gusterson BA, Shipley JM: Comparative genomic hybridization analysis of lobular carcinoma in situ and atypical lobular hyperplasia and potential roles for gains and losses of genetic material in breast neoplasia. Cancer Res 1998, 5820:4721-4727.

33. Nishizaki T, Chew K, Chu L, Isola J, Kallioniemi A, Weidner N, Waldman FM: Genetic alterations in lobular breast cancer by comparative genomic hybridization. Int J Cancer 1997, 74: 513-517.

34. Lakhani S, Collins N, Sloane J, Stratton M: Loss of heterozygosity in lobular carcinoma in situ of the breast. $J$ Clin Pathol: Mol Pathol 1995, 48:M74-M78.

35. Nayar R, Zhuang Z, Merino MJ, Silverberg SG: Loss of heterozygosity on chromosome 11q13 in lobular lesions of the breast using tissue microdissection and polymerase chain reaction. Hum Pathol 1997, 28:277-282.

36. Keller G, Vogelsang H, Becker I, Hutter J, Ott K, Candidus S, Grundei T, Becker KF, Mueller J, Siewert JR, Hofler H: Diffuse type gastric and lobular breast carcinoma in a familial gastric cancer patient with an E-cadherin germline mutation. $A m \mathrm{~J}$ Pathol 1999, 155:337-342.

37. Peralta Soler A, Knudsen KA, Salazar H, Han AC, Keshgegian AA: $P$-cadherin expression in breast carcinoma indicates poor survival. Cancer 1999, 86:1263-1272.

38. Droufakou S, Deshmane V, Roylance R, Hanby A, Tomlinson I, Hart IR: Multiple ways of silencing E-cadherin gene expression in lobular carcinoma of the breast. Int J Cancer 2001, 92. 404-408.

39. Roylance R, Droufakou S, Gorman P, Gillett C, Hart IR, Hanby A, Tomlinson I: The role of E-cadherin in low-grade ductal breast tumourigenesis. J Pathol 2003, 200:53-58.

40. Berx G, Cleton-Jansen AM, Nollet F, de Leeuw WJ, van de Vijver $\mathrm{M}$, Cornelisse $\mathrm{C}$, van Roy $\mathrm{F}$ : E-Cadherin is a tumour/invasion suppressor gene mutated in human lobular breast cancers. EMBO J 1995, 14:6107-6115.

41. Vos CB, Cleton-Jansen AM, Berx G, de Leeuw WJ, ter Haar NT, van Roy F, Cornelisse CJ, Peterse JL, van de Vijver MJ: E-cadherin inactivation in lobular carcinoma in situ of the breast: an early event in tumorigenesis. $\mathrm{Br} J$ Cancer 1997, 76:11311133.

42. Gamallo C, Palacios J, Suarez A, Pizarro A, Navarro P, Quintanilla $M$, Cano A: Correlation of E-cadherin expression with differentiation grade and histological type in breast carcinoma. $A m \mathrm{~J}$ Pathol 1993, 142:987-993.

43. Rasbridge SA, Gillett CE, Sampson SA, Walsh FS, Millis RR: Epithelial (E-) and placental (P-) cadherin cell adhesion molecule expression in breast carcinoma. J Pathol 1993, 169:245250.

44. Jacobs TW, Pliss N, Kouria G, Schnitt SJ: Carcinomas in situ of the breast with indeterminate features: role of E-cadherin staining in categorization. Am J Surg Pathol 2001, 25:229-36.

45. Maluf HM, Swanson PE, Koerner FC: Solid low-grade in situ carcinoma of the breast: role of associated lesions and E-cadherin in differential diagnosis. Am J Surg Pathol 2001, 25:237244.

46. Rahman N, Stone JG, Coleman G, Gusterson B, Seal S, Marossy A, Lakhani SR, Ward A, Nash A, McKinna A, A'Hern R, Stratton MR, Houlston RS: Lobular carcinoma in situ of the breast is not caused by constitutional mutations in the E-cadherin gene. $\mathrm{Br} J$ Cancer 2000, 82:68-70.

47. Bratthauer GL, Moinfar F, Stamatakos MD, Mezzetti TP, Shekitka KM, Man YG, Tavassoli FA: Combined E-cadherin and high molecular weight cytokeratin immunoprofile differentiates lobular, ductal, and hybrid mammary intraepithelial neoplasias. Hum Pathol 2002, 33:620-627.

48. Page DL, Rogers LW: Combined histologic and cytologic criteria for the diagnosis of mammary atypical ductal hyperplasia. Hum Pathol 1992, 23:1095-1097.

49. Rosai J: Borderline epithelial lesions of the breast. Am J Surg Pathol 1991, 15:209-221

50. Schnitt SJ, Connolly JL, Tavassoli FA, Fechner RE, Kempson RL Gelman R, Page DL: Interobserver reproducibility in the diagnosis of ductal proliferative breast lesions using standardized criteria. Am J Surg Pathol 1992, 16:1133-1143.

51. Sloane JP, Ellman R, Anderson TJ, Brown CL, Coyne J, Dallimore NS, Davies JD, Eakins D, Ellis IO, Elston CW: Consistency of histopathological reporting of breast lesions detected by screening: findings of the U.K. National External Quality Assessment (EQA) Scheme. Eur J Cancer 1994, 30A:14141419.

52. Lakhani SR, Collins N, Stratton MR, Sloane JP: Atypical ductal hyperplasia of the breast: clonal proliferation with loss of heterozygosity on chromosomes $16 q$ and $17 p$. J Clin Pathol 1995, 48:611-615. 
53. Amari M, Suzuki A, Moriya T, Yoshinaga K, Amano G, Sasano H, Ohuchi N, Satomi S, Horii A: LOH analyses of premalignant and malignant lesions of human breast: frequent LOH in $8 p, 16 q$, and 17q in atypical ductal hyperplasia. Oncol Rep 1999, 6: 1277-1280.

54. Gong G, DeVries S, Chew KL, Cha I, Ljung BM, Waldman FM: Genetic changes in paired atypical and usual ductal hyperplasia of the breast by comparative genomic hybridization. Clin Cancer Res 2001, 7:2410-2414.

55. Lakhani S, Slack D, Hamoudi R, Collins N, Stratton M, Sloane J: Detection of alleleic imbalance indicates that a proportion of mammary hyperplasia of usual type are clonal, neoplastic proliferations. Lab Invest 1996, 74:129-135.

56. Washington $\mathrm{C}$, Dalbegue $\mathrm{F}$, Abreo F, Taubenberger JK, Lichy JH: Loss of heterozygosity in fibrocystic change of the breast: genetic relationship between benign proliferative lesions and associated carcinomas. Am J Pathol 2000, 157:323-329.

57. Jones C, Merrett S, Thomas VA, Barker TH, Lakhani SR: Comparative genomic hybridization analysis of bilateral hyperplasia of usual type of the breast. $J$ Pathol 2003, 199:152-156.

58. Goldstein NS, O'Malley BA: Cancerization of small ectatic ducts of the breast by ductal carcinoma in situ cells with apocrine snouts: a lesion associated with tubular carcinoma. Am J Clin Pathol 1997, 107:561-566.

59. Fraser JL, Raza S, Chorny K, Connolly JL, Schnitt SJ: Columnar alteration with prominent apical snouts and secretions: a spectrum of changes frequently present in breast biopsies performed for microcalcifications. Am J Surg Pathol 1998, 22: 1521-1527.

60. Moinfar F, Man YG, Bratthauer GL, Ratschek M, Tavassoli FA: Genetic abnormalities in mammary ductal intraepithelial neoplasia-flat type ("clinging ductal carcinoma in situ"): a simulator of normal mammary epithelium. Cancer 2000, 88: 2072-2081.

61. Deng G, Lu Y, Zlotnikov G, Thor AD, Smith HS: Loss of heterozygosity in normal tissue adjacent to breast carcinomas. Science 1996, 274:2057-2059.

62. Larson PS, de las Morenas A, Cupples LA, Huang K, Rosenberg CL: Genetically abnormal clones in histologically normal breast tissue. Am J Pathol 1998, 152:1591-1598.

63. Lakhani SR, Chaggar R, Davies S, Jones C, Collins N, Odell C, Stratton MR, O'Hare M: Loss of heterozygosity ( $\mathrm{LOH}$ ) in normal luminal and myoepithelial cells of the breast. $J$ Pathol 1999, 189:496-503.

64. Li Z, Moore DH, Meng ZH, Ljung BM, Gray JW, Dairkee SH: Increased risk of local recurrence is associated with allelic loss in normal lobules of breast cancer patients. Cancer Res 2002, 62:1000-1003.

\section{Correspondence}

Sunil R Lakhani, The Breakthrough Toby Robins Breast Cancer Research Centre, Institute of Cancer Research, Mary-Jean Mitchell Green Building, Chester Beatty Laboratories, Fulham Road, London SW3 6JB, UK. Tel: +44 (0)20 7153 5525; fax: +44 (0)20 7153 5533; e-mail: Sunil.Lakhani@icr.ac.uk 